Adriana Ferreira Sousa ${ }^{1}$ Andréa Zemp Santana do Nascimento ${ }^{2}$ Juliana Araújo Silva ${ }^{3}$

1 Arquiteta, MPA Pedreira de Freitas Arquitetos Associados. Rua Fiação da Saúde, 128, Bloco C1, apto. 38. Jardim da Saúde, São Paulo, SP, Brasil. 04.144-020. afsous16@yahoo.com.br ${ }^{2}$ Pós-graduanda em Arte-educação, Universidade de Artes de Zurique.

${ }^{3}$ Mestranda em Psicologia Clínica, Universidade Estadual Paulista, Unesp, campus de Assis.

"Projeto financiado pelo Fundo de Cultura e Extensão Universitária da USP (FCEx), bolsas e recursos materiais, ago/2007 a abr/2008.

\title{
TEREMOS UM TÍTULO?
}

\section{ENCONTRAM-SE}

- Estudantes de Arquitetura, Pedagogia e Terapia Ocupacional da USP

- Moradores, sobretudo as crianças e os membros do setor de Educação, de um assentamento do MST.

Objetivo: Construir? Constituir? de forma conjunta um brinquedo-espaço, ou seja, uma estrutura espacial que abrigasse

diversas possibilidades de apropriação, e que tivesse efeito potencial de intensificar relações

sociais no espaço coletivo em

geral, introduzindo o lúdico como um aspecto do cotidiano.

\section{MOVIMENTO 0 -SO (posição inicial)-}

O MST convidou a Faculdade de Arquitetura da USP a pensar/estruturar conjuntamente com os moradores do assentamento Dom Pedro Casaldáliga o Sistema de Espaços Livres, atividade que constitui disciplina optativa. Fez parte desse encontro a interação entre algumas arquitetas, ou quase, e as crianças do assentamento, para que estas também se envolvessem na ação de transformação de seus ambientes. Objetivos-prazos da disciplina e a escolha "do que interessava" nessa interação se distanciaram... e aumentaram a abrangência do plano e o prazo para sua realização.

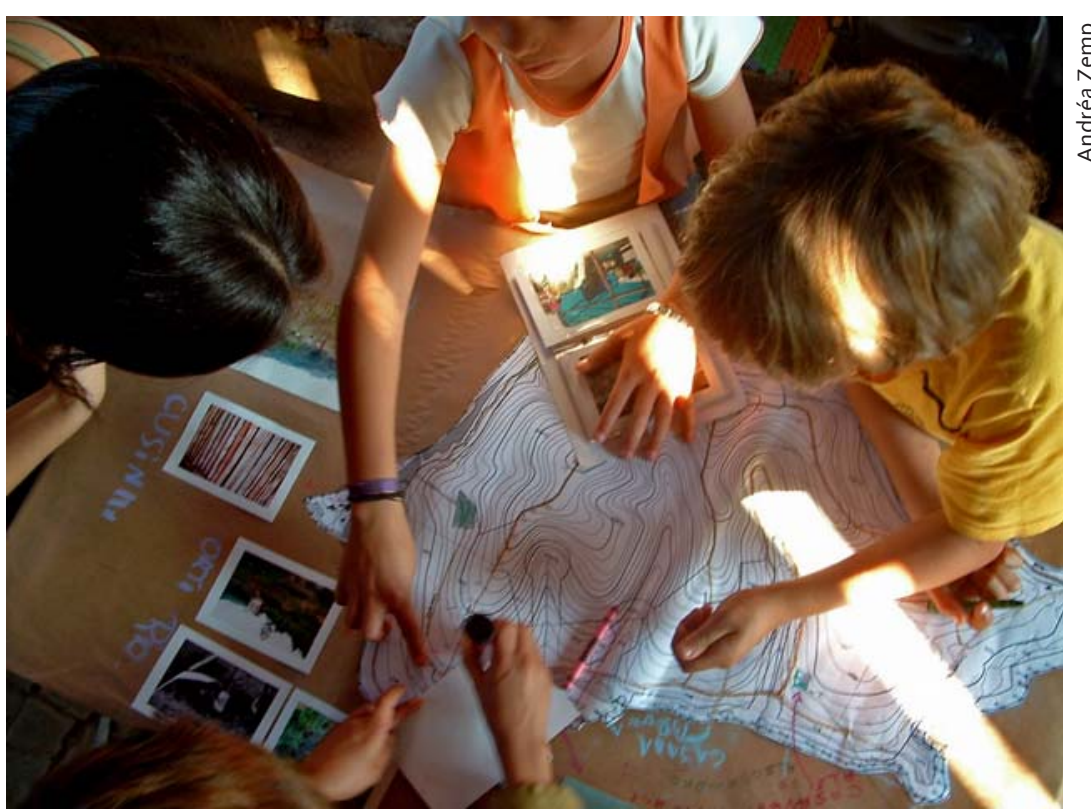


"Movimento é a ação dos bailarinos quando usam o corpo para criar formas ordenadas; a energia fornece a força necessária para executar o movimento; ritmo é o padrão de tempo em torno do qual se realiza o movimento e a criação está relacionada com a forma visual apresentada pelo movimento do corpo do bailarino."

(http://www.edukbr.com.br/artemanhas/tiposdedanca.asp)

O projeto em debate com os adultos se estendia para uma escala mais ampla - os espaços de produção e moradia do assentamento todo - e se tornava abstrato demais para as crianças, temporal e espacialmente. Com as crianças, o que seria executado não se sabe quanto tempo depois, era vago e não permitia ligações entre este abstrato e o concreto, inibindo uma possível experiência de conquista de autonomia. Sem possibilidade técnica para intervir em tal plano, estas teriam sempre uma posição coadjuvante em sua elaboração, quase como uma presença supérflua, por conta das variáveis que afligiam os adultos. Era latente a tomada de poder pelo efêmero, pelo fazer, pelo aqui-agora no processo com as crianças. Era preciso criar um outro espaço-tempo em sintonia com elas. Esta forma de conduzir o processo - forçando uma relação entre os processos com adultos e crianças e colocando as últimas em uma falsa posição de protagonistas - estava sendo prejudicial politicamente para as crianças, e, de certa forma, traduzia-se em submissão delas aos adultos. Nesse momento, também, percebíamos já a tensão: como nos posicionarmos em pensamento e em ação com relação às formas de infância produzidas socialmente?

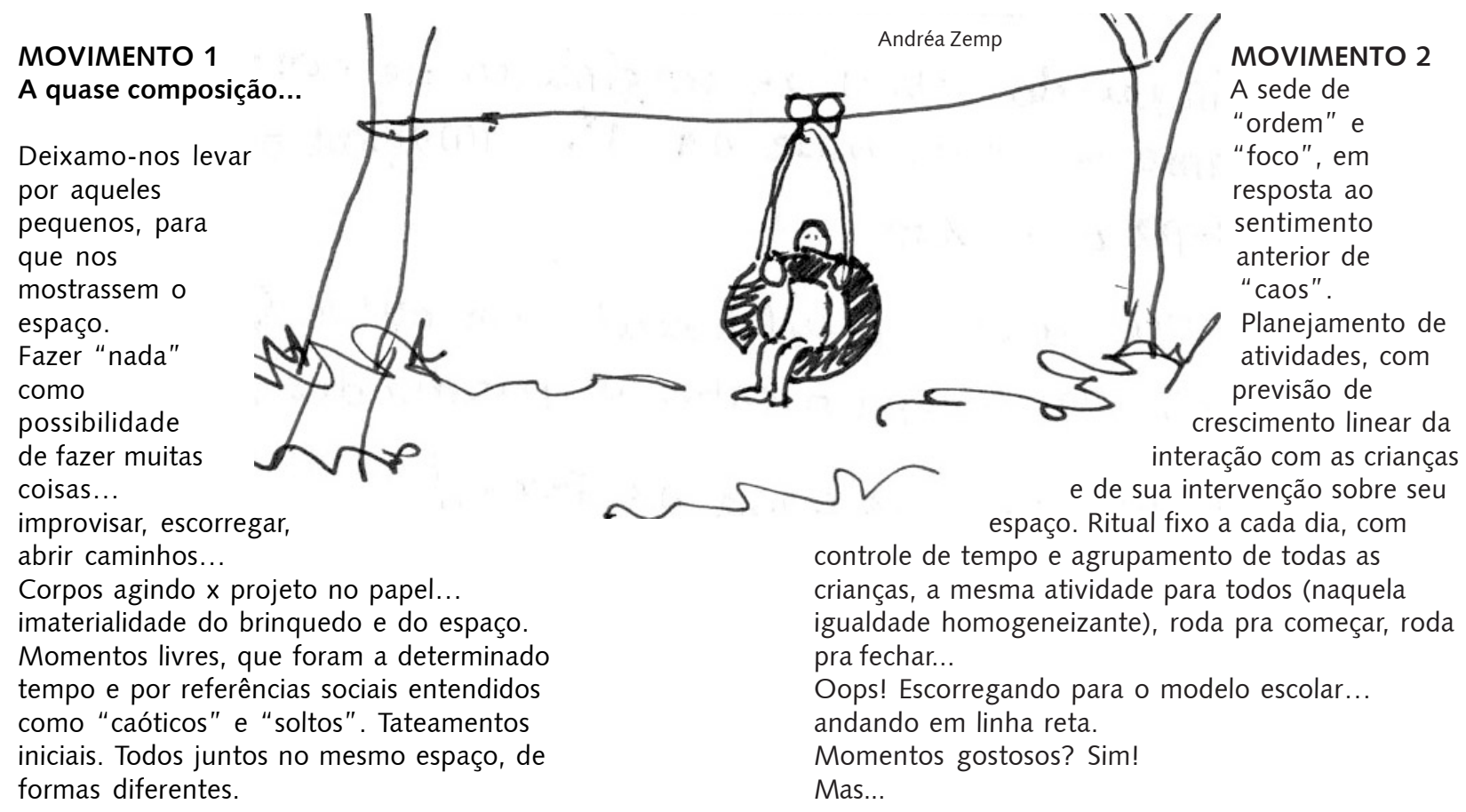




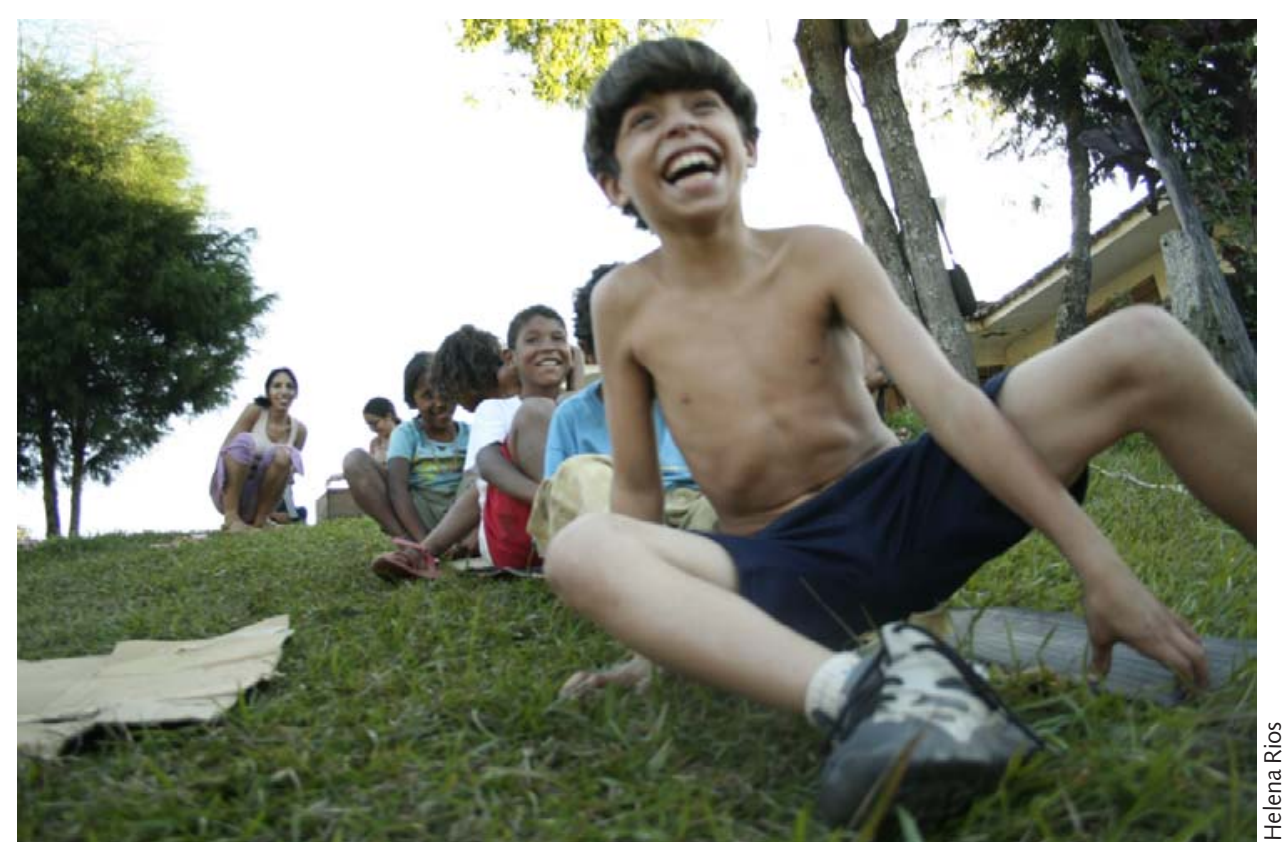

•윯

Areia, terra, argila, água... objetos, bichos, frutas,máscaras, personagens surgindo de paredes coloridas e do fundo do rio... crianças sumindo na areia e ressurgindo em malabarismos e saltos...
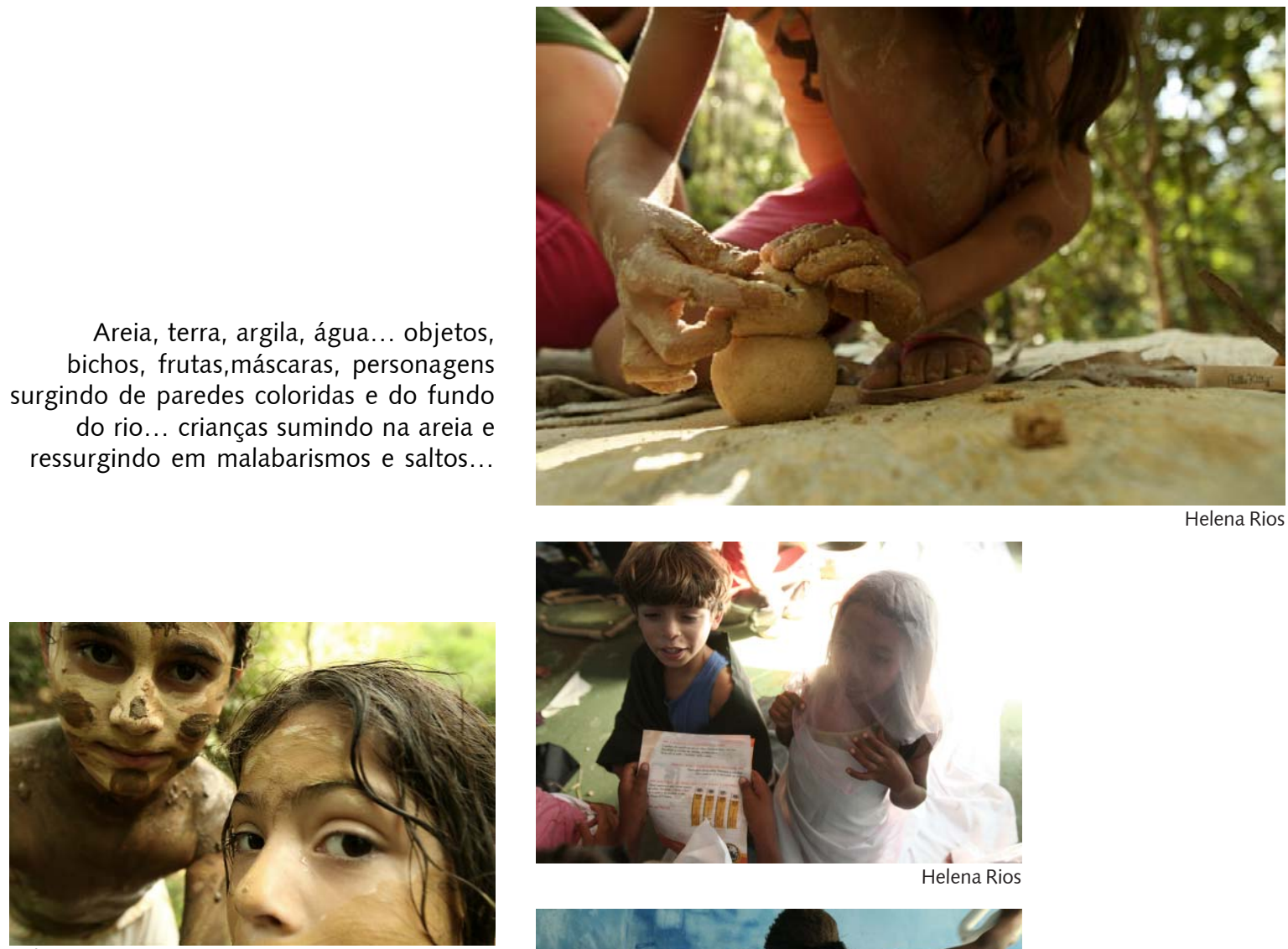

Helena Rios

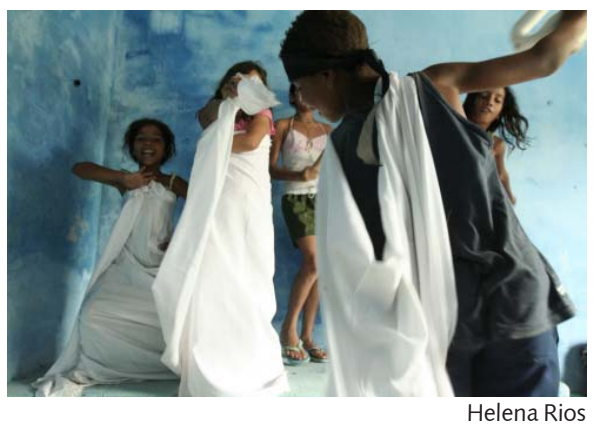

D2) Interface comunicaçäo saúde educcaçāo v.14, n.35, p.975-80, out./dez. 2010 


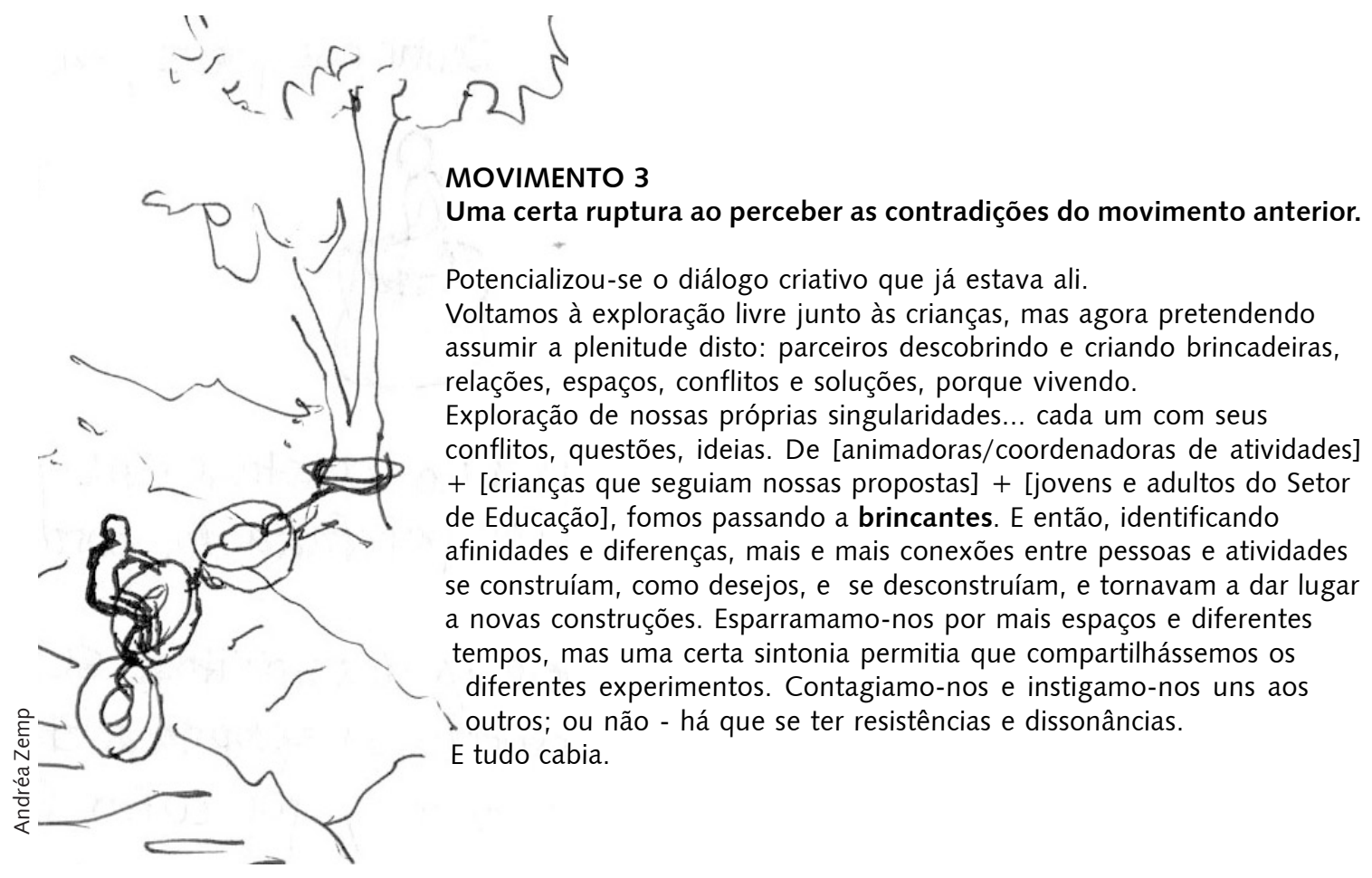

MOVIMENTO 4

Meses depois... as vivências e brincadeiras começam a se repetir... E agora? Será que estamos nos colocando de menos? Vamos brincar só de esconde-esconde? Sempre? Entendíamos como latente nossa interferência com materiais e propostas, que aglutinasse as

experiências vividas até ali, potencializando caminhos e também assumindo vontades nossas. Agora sim, e assim: tínhamos construída uma outra relação, com poderes revistos.

Planejamentos rígidos tinham perdido qualquer sentido. Desta interferência, surgiria uma multiplicidade de experimentações com vários graus de efemeridade. Pneus rodando ladeira abaixo, cordas e mais cordas, tecidos, tubos de papel... Corda-bamba, cipó de Tarzan, balanços, túneis, crianças entubadas, escadas, tirolesa, redes, piruetas e cambalhotas, circo, cabanas, crianças perdidas na floresta, mamães e filhinhas, homens da floresta, casinhas de pano quase suportando uma chuva de granizo!!!!, tubos destruídos por outrem, noivas, modelos e bandidos, cordas roubadas do assentamento...

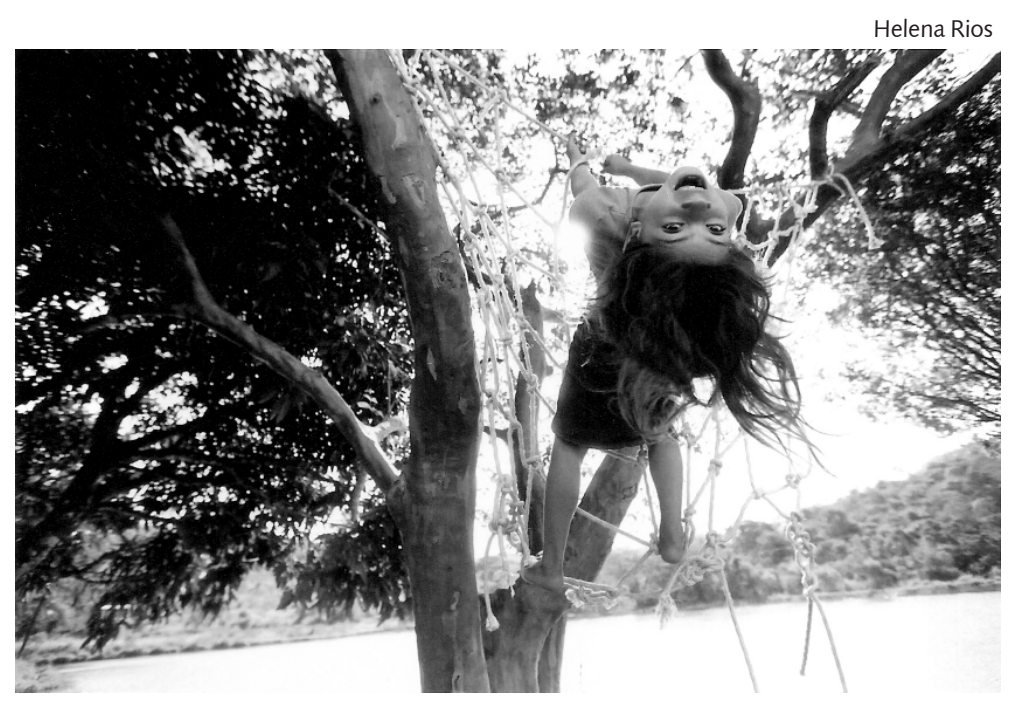

- "Não era assim que eu tinha imaginado não!"...

- "ela poderia estar presa no chão"...

- "ela poderia ser deitada!"...

- "e se ela fosse uma escada para uma casinha lá em cima?" 


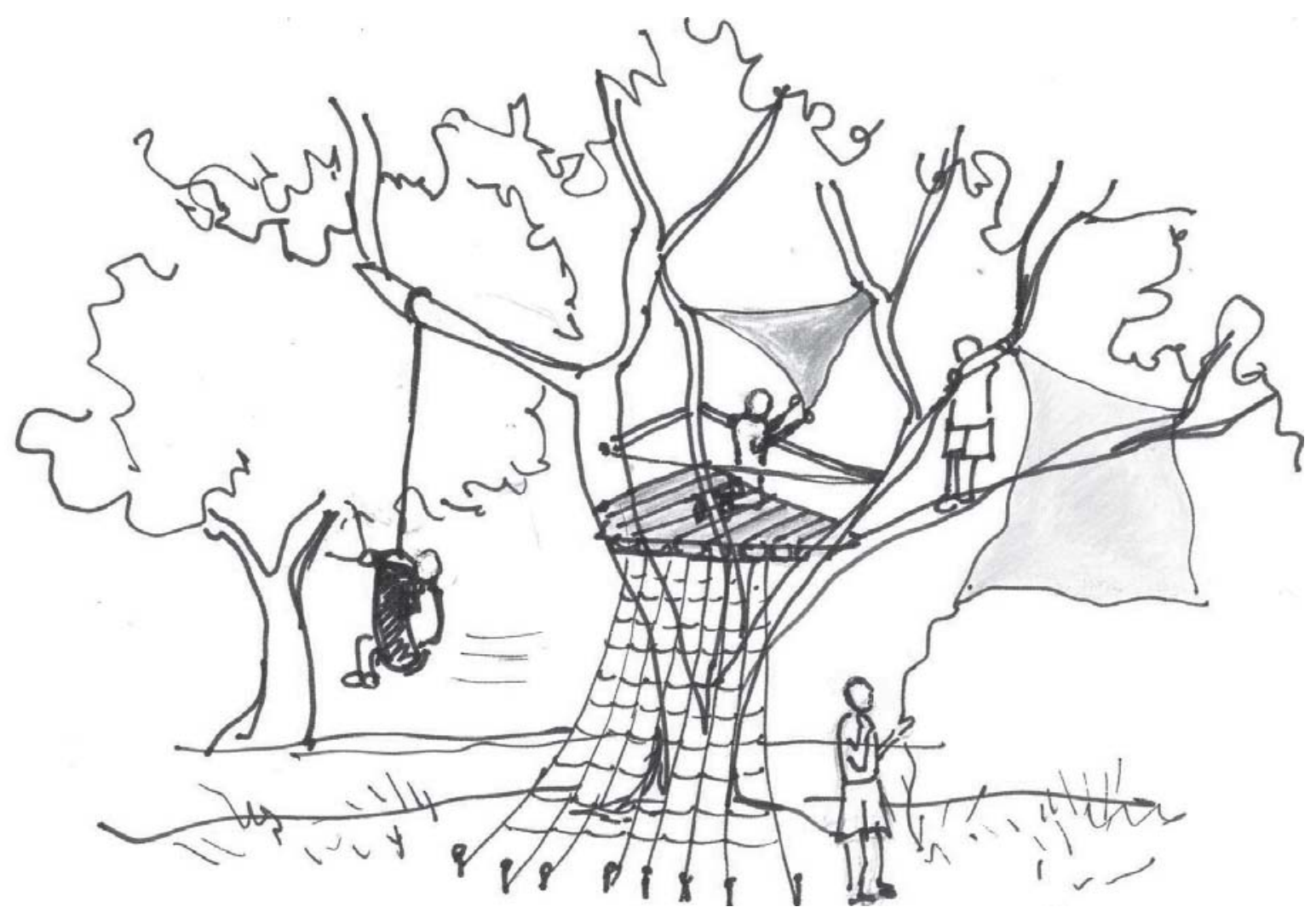

MOVIMENTOS QUE FICARAM POR VIR

Existia uma sinergia que foi se construindo entre nós aos poucos para a materialização de um marco físico de nossas vivências. Esta sinergia se potencializou num passeio que fizemos juntos ao SESC Itaquera, onde encontramos consolidadas algumas idéias esboçadas no imaginário, ainda sem forma, e outras que já tínhamos começado a materializar no assentamento. Uma casinha na árvore, com escadinhas, uma rede horizontal, pneus e outros elementos começavam a procurar lugar para instalação no nosso habitat comum. Uma plantação de bambu existia próximo ao assentamento. Unindose a tudo isso a versatilidade deste material e relativa facilidade de sua manipulação, tomou força no grupo a realização de uma oficina para todos do assentamento, que fosse uma ferramenta para futuras construções, lúdicas ou não. Agenciamos o arquiteto que poderia ensinar técnicas e organizamos o dia juntamente com o assentamento.

Fez-se assim uma finalização neste processo, que poderia ter desdobramentos imprevisíveis. 


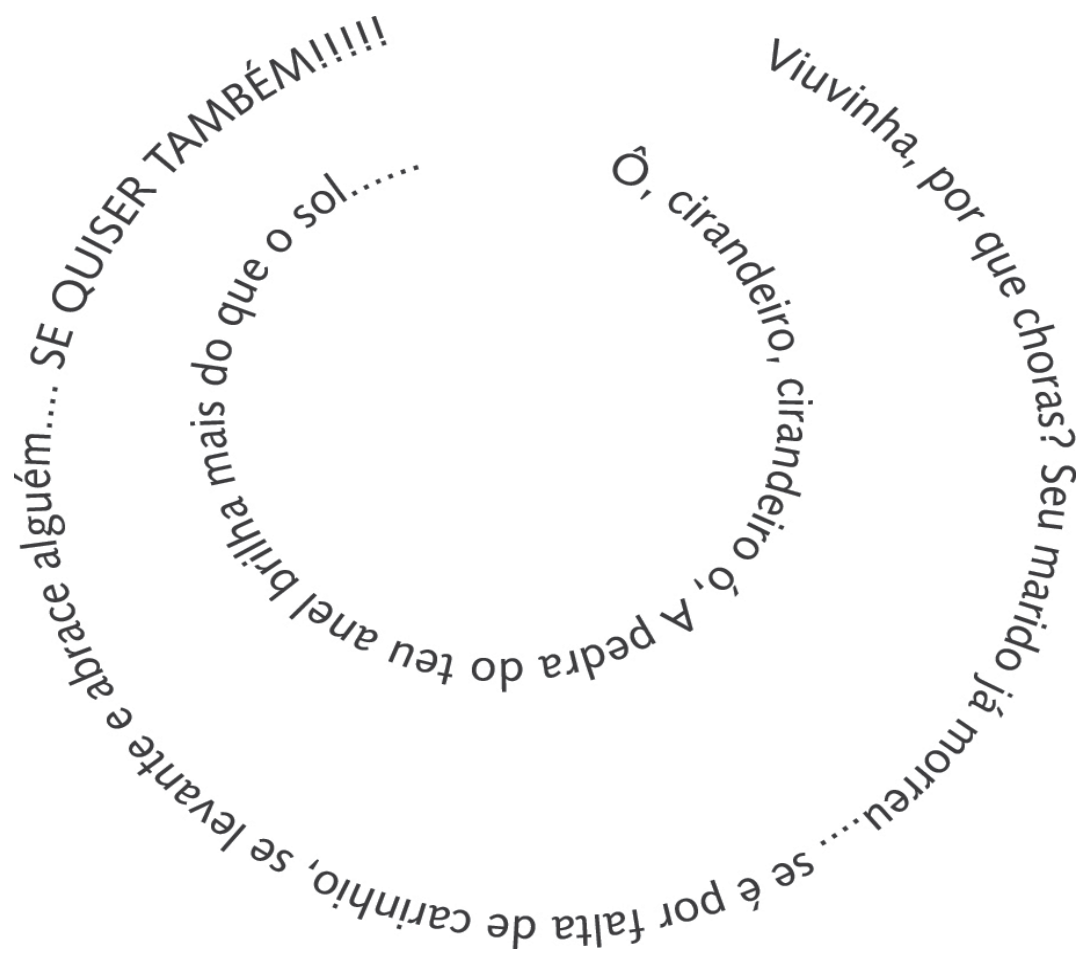

980 D) Interface comunicaçã̃o saúde Educação v.14, n.35, p.975-80, out./dez. 2010 